\title{
CEBPA Gene Mutation
}

National Cancer Institute

\section{Source}

National Cancer Institute. CEBPA Gene Mutation. NCI Thesaurus. Code C38372.

Mutation of the CEBPA gene encoding CCAAT/enhancer binding protein alpha. It is seen

in acute myeloid leukemias usually associated with a normal karyotype. 